\title{
Onafhankelijkheidspolitiek in agonie. Het oorlogsdagboek van een Hollander
}

\author{
H. W. VON DER DUNK
}

Albert E. Kersten, ed., Het dagboek van dr. G. H. C. Hart. Londen mei 1940-mei 1941 (Werken uitgegeven door het NHG, Vijfde serie VII; Den Haag: Martinus Nijhoff, 1976, 312 blz., $f 49,50)$.

Een groot tekort van het dagboek van dr. G. H. C. Hart is dat het slechts één jaar bestrijkt en in mei 1941 eindigt. Hoe graag zouden we zijn reacties op het wereldgebeuren ook daarna vernemen! Niet omdat hij altijd zo'n feilloos oordeel had maar omdat hij ten prooi viel aan zo interessante vergissingen en illusies. De grote keerpunten van de oorlog: de Duitse aanval op de Sovjet-Unie, Pearl Harbour en de Japanse storm over heel de Pacific, Nederlands-Indië inbegrepen en dan in de jaren 1942 en 1943 het kerende getij. We vernemen niet hoe hij dat alles verwerkt heeft. De uitgever is er blijkbaar ook niet in geslaagd om daarover iets te weten te komen.

Van alle egodocumenten is het dagboek voor de historicus het waardevolst, omdat we hier een mens in zijn onmiddellijke reacties zonder kennis van de afloop betrappen. We zien weer de beperkte horizon van waaruit hij destijds dacht en handelde, die bij alle memoires kunstmatig is verbreed, zo niet vervormd. In Nederland zijn we met politieke dagboeken nog minder gezegend dan met memoires. Maar dat is niet de enige reden, dat men Harts confessies zo geboeid uitleest. Hier stort een man dagelijks zijn ziel op papier uit, die zich opvreet in ballingschap, abrupt gescheiden van vrouw en kinderen, gedoemd tot eindeloze discussies, plannenmakerijen, adviezen aan ministers, die al even machteloos en vleugellam zijn als hij; gedoemd met andere woorden tot verregaande passieve activiteit. Terwijl de bommen maandenlang om hem heen op Londen regenen. De sfeertekening, die hij met deze spontane aantekeningen geeft van de Nederlandse autoriteiten in Londen, evenals van Engeland zelf tijdens dat zo wonderlijke jaar 1940, werpt een verrassend licht op een episode van de tweede wereldoorlog waar nog nauwelijks naar is omgekeken.

Wie was George Henry Charles Hart? Afkomstig uit een welgesteld Joods-Amsterdams gezin studeerde hij rechten en werkte zich na de eerste wereldoorlog als juridisch adviseur van de Suiker Werkgeversbond op Java snel omhoog. Tenslotte werd hij door gouverneurgeneraal De Jonge in 1934 benoemd tot directeur van economische zaken. Hij behoorde tot de delegatie, die in 1934 met Japan over de Japans-Indische handelsproblematiek onderhandelde. In 1937 nam hij ontslag om zuiver familiaire redenen en keerde naar Nederland terug, waar hij aan het departement van koloniën werd verbonden. Als hoofd van de economische afdeling verliet hij op last van zijn minister, Welter, Nederland op 14 mei 1940 om de regering naar Londen te volgen. Het is daaraan dat wij het dagboek te danken hebben.

Het verlangen naar vrouw en kinderen, de tergende zorg over hun lot, slechts door sporadische korte berichten via allerlei omwegen van tijd tot tijd even verlicht, het driftige ongeduld om weer naar een vrij Nederland terug te kunnen, vormen de dominante toon- 
aard. Dat maakt Hart zo menselijk in zijn stemmingswisselingen, vertwijfeling, opverende hoop. Hij overleed in Londen in augustus 1943, 50 jaar oud, aan kanker. De wetenschap dat zijn wens een droom zou blijven en dat zij, tot wie deze ontboezemingen waren gericht, ze pas na zijn dood zou lezen, maakt de lectuur achteraf bovendien tot een ontroerend document.

Toch ligt het historische belang natuurlijk niet in die menselijke kant maar in zijn reacties op de toestanden en gebeurtenissen om hem heen. In Hart ontmoeten we een bovenal economisch deskundige, die wat zijn politieke opvattingen aangaat het beste met rechtsliberaal getypeerd wordt; wat voor een gestudeerd man uit de beter gesitueerde JoodsAmsterdamse kringen een vrij natuurlijke standplaats was. In zijn dagboek blijkt hij terloops gelovig christen, maar wel van een zeer algemeen-vrijzinnige signatuur, waar nog bij komt dat de noodsituatie van oorlog en ballingschap zijn religiositeit allicht heeft versterkt. Het 'vertrouwen op God' in uitzichtloze situaties is een herhaaldelijk terugkerend motief. Dat hij in Indië bepaald niet tot de progressieven uit de hoek van de Stuw behoorde blijkt (afgezien van zijn relatie met Java-Suiker) uit zijn actief lidmaatschap van de Vaderlandse Club in Soerabaja. We mogen aannemen, dat de politieke en koloniale status-quo voor hem de maatstaf en alles wat zweemde naar meer medezeggenschap van de inlanders in het bestuur hem een gruwel was; al kwam hij wel op tegen economische exploitatie van de bevolking. Met name uit zijn koloniale loopbaan vloeide voort, dat hij in Nederland een krachtige natie zag, die vanouds een eigen onafhankelijke plaats had ingenomen en behoorde in te nemen. Daarin was hij stellig representatief voor de Nederlandse politieke elite tijdens het interbellum, die dankzij de lange ongebroken neutraliteitspolitiek en de betrekkelijk hoge welstand van het land, temidden van een chaotisch en dynamisch Europa, steeds meer in een sfeer van isolatie kwam te verkeren. Er was geen klemmende reden om de traditionele normen te herzien, zolang die normen een bruikbare basis voor de politiek leken te bieden. Het geloof in de voortreffelijkheid en rechtvaardigheid van het koloniale bewind, in 's lands roemvolle verleden, in zijn recht op een aandeel in de Westerse leiding op grond van zijn fatsoen en cultuur makkte wel de essentie uit van dit Nederlandse nationalisme.

De wrede confrontatie met nazi-Duitsland in mei 1940 kwam als een verdovende slag en het is interessant om het proces van innerlijke aanpassing en van omdenken te volgen, waartoe de politici werden gedwongen. Juist bij Hart blijkt dat hier inderdaad van een proces gesproken moet worden en dat het onmogelijk van vandaag op morgen ging.

Ook bij hem, evenals bij de overgrote meerderheid van de bevolking in en na de meidagen wanhopige verontwaardiging en ongeloof over wat het land is overkomen! De nederlaag was alleen mogelijk dankzij verraad:

Hollandsche soldaat als leeuw gevochten; plaats waardig gemaakt onder beste soldaten in wereld... ondanks geweldige verliezen deden troepen tot bittere einde hun plicht... Dolkstoot in rug door talrijke Duitschers achter linies geland en geholpen, door Vijfde Kolonne hadden dit besluit [de strijd te staken, v.d.D.] onvermijdelijk gemaakt...

heet het in het dagboek (9) en dan met vertwijfelde triomf: 'In ieder geval had vijand viermaal zoolang noodig voor uitvoering plannen als blijkens verscheidene aanwijzigingen berekend'. (9) We weten vandaag dat dit beeld niet klopt, maar kon de met nog half-negentiende-eeuwse militaire en politieke opvattingen geëquipeerde Nederlander anno 1940 anders reageren, wilde hij niet alle houvast en geloof in de toekomst verliezen? Zoals een vertekend realiteitsbeeld tot een debakel kan leiden, zo kan het omgekeerd trouwens ook de 


\section{H. W. VON DER DUNK}

voorwaarde voor succes zijn. Het illusionisme, dat Nederland als klein buurland van Duitsland niet vermocht te redden, heeft - in wat andere vorm - de Engelsen door de beslissende maanden heengeholpen naast andere factoren. Rationeel gesproken hadden de defaitisten in de zomer 1940 het gelijk aardig aan hun kant.

Opmerkelijker dan deze zo voor de hand liggende reactie zijn echter Harts aantekeningen in de komende maanden, waar zo duidelijk de nationale Hollander uit spreekt, die nog sterk in de termen van de vooroorlogse zelfstandigheidspolitiek denkt. Dat betekende: Nederland is een middel-grote mogendheid op zijn minst! Niet te vergelijken met België, Denemarken, Polen en al die andere slachtoffers van de nazi agressie; zelfs niet met Frankrijk. Dankzij zijn Indisch imperium is het niet minder dan Engeland en de VS de grote handhaver van de orde in de Pacific tegen Japanse dreiging en dankzij zijn rijkdom en scheepsruimte heeft het ergo ook recht op een soort bondgenootschappelijke voorkeursbehandeling door de Britten. Hart wil dat de Nederlandse regering haar eigen zelfstandige oorlogspolitiek ontwikkelt. Zij dient aankopen te doen om zodra Nederland weer vrij is 'en ik vrees wel, dat dit eerst bij een wapenstilstand of vrede zal kunnen zijn' (46) van alle kanten het land te kunnen bevoorraden; een verjongde constitutie en tegelijkertijd economische opleving, terwijl de rest van een zieltogende wereld 'bezig is te overwegen, hoe de nood zou kunnen worden gelenigd' (48), ziedaar Harts toekomstbeeld begin juli 1940! Terwijl in Europa Nederland en Engeland als bondgenoten tegenover Duitsland staan, mag dat geen invloed hebben 'op onzen vasten wil in Pacific onze beproefde zelfstandigheidspolitiek' voort te zetten. Er is geen enkele behoefte daar 'in welke combinatie ook verzeild te raken'... (53). Hetgeen dan wel een zeer merkwaardig soort bondgenootschap mag heten: waar Nederland zich sterk voelt gaat het zoals vanouds zijn eigen gang, waar het op Engeland is aangewezen beschouwt het zich als diens bondgenoot! Om die fiere politiek te kunnen voeren dient de regering zich dan ook naar Indië, naar haar eigen territoor te begeven. Dit zogenaamde 'grote plan' stuit onder andere dadelijk af, tot Harts teleurstelling, op de onwil van koningin Wilhelmina, die niet tegen de warmte kon. 'Het is ontzettend, dat een Oranje zulk een argument bezigt' (30). Zij komt dan met het 'kleine plan' om enkele ministers te sturen, waarbij uiteraard de wezenlijke oogmerken van Hart worden miskend. Nog maandenlang spookt dit 'kleine plan' in de debatten rond en het wordt uiteindelijk in februari 1941 in nog weer sterk verkleinde vorm uitgevoerd. Koningin en regering echter blijven in Londen, waar zij machteloze ballingen zijn; aangewezen in alles, ook in uiterlijke dingen op de Britse welwillendheid.

Geen wonder, dat Hart zich doorlopend opwindt over de ministers, die zo hun taak en de Hollandse waardigheid te grabbel gooien in zijn ogen. Zijn beeld is vernietigend: afgezien van zijn eigen minister Welter, die hij slechts zijn grote somberheid verwijt en Steenberghe, vindt hij het een stelletje incompetente slapjanussen; gedemoraliseerde defaitisten, van wie enigen zoals De Geer en Van Rhijn voor Hitlers rijk willen buigen en in zijn overwinning berusten en de rest (vooral Gerbrandy en Van Kleffens worden in dit verband genoemd) al even fantasie- en stuurloos achter de Engelsen aan sukkelt. Voor Harts 'zelfstandigheidskoers' is geen meerderheid te vinden. Evenzeer stoot hij zich aan zijn collega mr. W. G. Peekema, hoofd van de juridische afdeling van koloniën; een cynische pessimist, die berust in de loop der dingen en de van huis uit al zwartgallige Welter telkens weer omlaag trekt naar zijn 'blijmoedig' fatalisme. De meesten van de heren 'kunnen zich nauwelijks in de Engelse taal verstaanbaar maken: diploma MULO moest in den vervolge voor ministers worden geeischt'(32).

Wanneer Hitler midden juli zijn voelhorens uitsteekt om vrede te sluiten met Engeland vindt Hart dat deze kans niet mag worden verzuimd. Zijn meiwoede heeft duidelijk plaats 
gemaakt voor een geprikkelde stemming jegens de Engelsen. Daarbij spreekt vermoedelijk ook weer zijn koloniale verleden een rol; de latente concurrentiegevoelens tussen de oude zeemogendheden waren aan Nederlandse zijde nooit verdwenen en voor het Indische bestuur was zelfs het Duitsland van Hitler veel en veel verder weg dan de Britse 'Commonwealth'.

Ook Harts Joodse origine verandert daar blijkbaar niets aan. Het antisemitisme van de nazis speelt in zijn beschouwingen nauwelijks mee. Voor Nederland verwacht hij er blijkbaar geen speciale moeilijkheden van. Het is meer, dat men met deze eigenaardigheid van het regime nu eenmaal rekening moet houden, op grond waarvan hij het niet verstandig acht, zoals terloops blijkt, dat het Joodse element in Londen en elders al te nadrukkelijk op de voorgrond treedt. Van de felle anti-nazistische journalisten 'natuurlijk voornamelijk rasgenoten van mij' (128) moet hij in die maanden al heel weinig hebben.

Als men hen hun gang laat gaan emaneert er van hen in de pers en via de radio een goedkope en onwaardige Hetze tegen Duitsland en wat jullie via de radio van hier aan stijlloosheid en goedkope moed krijgen, komt meestal uit dien hoek (128).

De Nederlandse regering moet de Engelsen benaderen om Hitlers vredeshand te grijpen. Halifax - oude medewerker van Chamberlain, minister van buitenlandse zaken al tijdens München - lijkt hem hiervoor het adres; een verstandiger en realistischer man dan Churchill. Plessmans wonderlijke bemiddelingspoging, waarbij die aan Göring vredesvoorstellen vroeg en deze naar Engeland doorspeelde, vindt Hart dan ook een zaak, die het kabinet moet ondersteunen. Hij is woedend over wat hij een dwaas en onrealistisch Victorygeschreeuw van de Engelsen vindt. Er is immers geen enkele kans dat Engeland de oorlog nog wint. Dat hij voor Churchill, die wil doorzetten tot de vernietiging van het nazisme, weinig sympathie opbrengt, behoeft dan ook niet te verbazen: wat een waanzinspolitiek, waarbij heel Europa zal worden vernield! Maar Harts vredesverlangen - vooral toch ingegeven omdat hij Nederland, zijn gezin terug wil zien en het niet meer uit kon houden in dat afgesloten incestueuze Londense ambtenarenwereldje - betekent niet dat hij een vrede op Duitse voorwaarden zou aanvaarden. Onveranderlijk zet hij zich fel af tegen het defaitisme à la de Geer. Nee, Nederland moet zijn volledige onafhankelijkheid terugkrijgen.

... men begrijpt niet, dat er een enormen afstand ligt tusschen hem, die met de Duitschers den eervollen vrede wil, die thans mogelijk en noodig is om Europa van bolsjewiseering en ondergang te redden en hem, die den oorlog als verloren beschouwt en bereid is 't hoofd te buigen en te capituleren... (63).

Wanneer de Britse regering de Duitse boot afhoudt en de Nederlandse regering niet, zoals Hart wil, tracht te bemiddelen, vindt hij dat ze de Engelsen duidelijk moet maken, dat hun wegen zouden kunnen scheiden. Vichy-Frankrijk en Pétain worden zijn lichtend voorbeeld. De Fransen zijn realisten en spelen een superieur spel, zich losmakend van de Duits-Engelse oorlogswaanzin. Nederland zou op eigen houtje met de Duitsers moeten onderhandelen 'je m'en fiche de Polen en Tsjechoslowakije, Danzig et du Corridor' (88). Een standpunt, dat Hart, zij het met lichte schommelingen, volhoudt tot diep in de herfst en winter: nadat de luchtslag om Engeland gestreden en feitelijk voor de Duitsers op een echec uitgelopen is; nadat de dreigende invasieplannen van de baan zijn; kortom, nadat Engelands zwaarste uur gepasseerd is; gepasseerd óók in de ogen van zeer vele tijdgenoten en van bezet Europa, waar na de kritieke zomer- en herfstmaanden de Duitse eindover- 
winning al kwestieus werd geacht. Ook Hart acht die dan kwestieus; en daarom verwacht hij dat de Duitsers voor een redelijke vrede te vinden zijn.

Een illusionisme, dat verbijsterend aandoet... Hitler eventueel bereid om Nederland zijn volle onafhankelijkheid terug te geven op het moment dat heel West- en CentraalEuropa in zijn macht zijn en Engeland weigert de wapens neer te leggen! Om dit te verklaren moeten drie factoren in rekening gebracht worden: bovenal Harts persoonlijk verlangen naar huis. Daarnaast echter ook dat vooroorlogse onafhankelijkheidsbesef, gekoppeld aan een traditionalistische opvatting van de internationale verhoudingen, waarbij de sterke ideologisering van de politiek, de doordrenking ook van de machtstegenstellingen met ideologische ingrediënten nog niet is verdisconteerd. Hoe weinig Hart vanzelfsprekend ook van de nazis moet hebben - in zijn ogen eerloze laaghartige kornuiten, schenders van recht en fatsoen - kennelijk gaat hij er van uit, dat hun heerschappij de Duitse samenleving en daarmee ook het vaste en rationele kader van de Duitse politiek niet wezenlijk heeft aangetast. En tenslotte is er de bolsjewistenvrees van de liberaal. In dit opzicht erkent hij wél een ideologisering van de politiek. Het is net of die ideologisering, die door het bolsjewisme vanaf 1917 in de internationale verhoudingen is gebracht volop is begrepen en verwerkt; ja, dat zij zelfs door liberalen en reactionairen is overschat, terwijl diezelfde ideologisering in het geval van het fascisme niet is begrepen. Het besef, dat Duitsland volop deel uitmaakte van de beschaafde Europese landenkring in tegenstelling tot het verre Aziatische Rusland, evenals de tweeslachtige ideologische standplaats en oorsprong van het fascisme, zal tot dat verschil in taxatie hebben bijgedragen.

Dat mengsel nu van anti-bolsjewisme, afkeer van Hitler en zijn makkers persoonlijk en toch geloof in de mogelijkheid van een redelijke schikking met Duitsland, voortvloeiend uit onbegrip voor de dynamiek van het nationaalsocialisme en de krachten, die het heeft losgemaakt, was tekenend voor de appeasers in de jaren 1936-1939 en in zoverre bewijst Hart nog eenmaal, hoe diep geworteld dat denken niet alleen natuurlijk bij de Nederlandse toplaag maar bij de West-Europese toplaag was. Terwijl in Engeland door de ervaringen in het jaar 1939 (annexatie van de Tsjechische rompstaat, conflict met Polen) echter gaandeweg het inzicht in die irrationele nationaalsocialistische dynamiek doorbrak, had men in het neutrale Nederland nog langer nodig. Juist een liberaal had vanuit zijn traditioneel fatsoensbegrip en rationeel mensbeeld zo'n moeite met dat verschijnsel.

Pas in het voorjaar 1941 als Hitler Joegoslavië overmeestert, gaat Hart overstag: nu acht hij vrede met nazi-Duitsland uitgesloten. Nederland moet aan de zijde van Engeland tot de overwinning blijven doorvechten. Zijn waardering voor het stugge Engelse volhouden, ook voor de moraal van de bevolking is in de winter- en voorjaarsmaanden na de maandenlange bombardementen geleidelijk groter geworden.

Op één punt - maar het is wel een zeer essentieel punt - kan men achteraf dan ook alleen maar van geluk spreken, dat het kabinet niet naar Hart geluisterd heeft. Een Nederlandse regering, die in de zomer en herfst 1940 bij Churchill op vrede had aangedrongen, zou zichzelf in een allerberoerdste positie hebben gemanoeuvreerd en nog veel meer respect hebben verspeeld dan ze deed door dat passieve luie achter de Engelsen aanlopen, dat Hart zo stak. Dat behoeft nog geen brevet van bekwaamheid en politiek inzicht voor Van Kleffens en Gerbrandy, de exponenten van de pro-Engelse koers te zijn. De rol van Van Kleffens ('.. een bekwaam hoofdambtenaar zonder enige staatsmanseigenschappen...', met name is nog onduidelijk. Enkele hartige woordjes van Hart aan diens adres zijn weggelaten (144). Maar we kunnen dan toch op zijn minst van een gelukkige passiviteit, een heilzame sloomheid in dit opzicht spreken; van een juist instinct, dat na de meidagen Nederlands weg aan Engelands zijde lag; een instinct dat ook koningin Wilhelmina bezat. 
De laatste wordt overigens in deze pagina's aardig van het voetstuk gesleurd, waar ze, wat haar Londense tijd betreft, op heeft gestaan. Zeker ... van echt defaitisme was bij haar geen sprake en dat zij de ongelukzalige De Geer, die zo volslagen achterliep bij zijn tijd, tot aftreden heeft gedwongen ten behoeve van Gerbrandy, was een goede daad. Maar een daad, die zoals alles bij Wilhelmina voortvloeide minder uit realisme en politiek inzicht, dan uit een mengsel van gezond instinct en koppig steile religiositeit, die haar uit godsdienstig oogpunt verbood om voor een verworpene, een baarlijke satan als Hitler ooit te kapituleren. Wanneer Welter in februari 1941 afscheid neemt voor zijn vertrek naar Indië verwacht zij 'binnen enkele dagen oorlog met Japan' en meent 'we moeten ze maar eens flink aanpakken en als ratten verdrinken' (258). Een weinig vorstelijke en weinig christelijke ontboezeming tekent Hart hierbij aan.

Bij zijn eerste audiëntie vindt hij haar

een koele en strenge oude dame, die weinig charme heeft: ik voelde mij op bezoek bij de straffe directrice van een lyceum; zoo iets als op een ouderavond, als je zoon niet zulk een bijster goed rapport heeft thuis gebracht (181).

Wanneer ze (weer bij dat afscheidsgesprek met Welter) ook in Duitsland elk moment een revolutie verwacht en een 'tot ziens in juni in Holland' uitspreekt, vraagt men zich inderdaad even met Hart af, door welke mensen zij geïnformeerd werd en hoe haar realiteitsbeeld er eigenlijk uitzag.

Het is dus geen erg imponerend tafereel van de hoogste Nederlandse vluchtelingenkring in Londen, dat hier verrijst. Dat onderlinge verdachtmakerijen, intriges, kleine vetes moesten opbloeien in ballingschap, in het door bommen geteisterde verduisterde Engeland tussen al die ontwortelde, van macht beroofde, bijeenhokkende heren, die zo door het vreedzame conservatieve Nederland uit de interbellaire periode waren gevormd... kon het eigenlijk wel anders? Moeizaam moesten zij zich trachten aan te passen, ook Hart. En zijn opvatting van Nederlands politieke en economische betekenis als praktisch grote mogendheid, die bij de bondgenoot krachtig op zijn poot zou kunnen spelen, komt in een ander licht te staan, wanneer we bedenken hoe hardnekkig zich dergelijke ideeën nog na de oorlog in conservatieve kringen hebben gemanifesteerd bij de Indonesische kwestie. Tekenend voor het vooroorlogse nationale bewustzijn is misschien ook Harts neiging om af en toe zijn patriotisme in verzen uit te leven. Die drang om 'politiek en poësie' te verbinden is bij ons wel uiterst zeldzaam geworden. Het was echter een normaal verschijnsel bij de nationale burgerij, die zich in de vorige eeuw ontwikkelde tot drager van staat en natiebesef. Het nationalisme inspireerde overal de geesten tot geversificeerde ontboezemingen, zelfs in Nederland. Hart is woedend dat een van zijn zangen, bestemd voor het Londonse Vrij Nederland, door hoofdredacteur Van Blankenstein met beleefde dank werd afgewezen.

Het is alleen maar te wensen dat er nog meer persoonlijke getuigenissen te voorschijn komen, die ons over die jaren berichten, al zullen ze niet gauw Harts dagboek evenaren. De uitgever Albert E. Kersten verdient in elk geval voor deze doorgaans verzorgde editie alle erkentelijkheid, evenals het Nederlands Historisch Genootschap voor het initiatief. 


\section{Recensies}

P. L. Nève, Het Rijkskamergerecht en de Nederlanden: competentie - territoir - archieven (Maaslandse Monografieën, XIV; Assen: Van Gorcum \& Comp., 1972, ISBN 90232 09559 en (geb.:) 902320987 7).

Voor zijn onderzoek naar de rol van het Rijkskamergerecht (RKG) in de Nederlanden koos dr Nève een opzet, die geleid heeft tot een onevenwichtig en onhandig gecomponeerd, maar uiterst nuttig boek over de competentie en het territorium van dit orgaan en de functie van 'rijksonmiddellijke' vorstjes in een gebied dat praktisch met de huidige Benelux overeenkomt. Schrijver onderzocht met name de relatie van de kleine, buiten het Verdrag van Augsburg (1548) gebleven, vorstendommetjes en heerlijkheden tot het Duitse Rijk.

Hij begint zijn studie met een zeer uitvoerige inleiding over de geschiedenis van het RKG tot 1806 en een niet minder breed overzicht van de samenstelling en organisatie ervan. Het is zeer de vraag, of een zo gedetailleerde behandeling van een materie waarover weinig nieuws te brengen valt, hier nodig was: het lijkt een wel erg lange omweg naar het doel dat schrijver zich stelde. Ook het tweede hoofdstuk over de territoriale competentie van het RKG maakt ten dele een overbodige indruk, gevuld als het is met handboekenkennis omtrent de geschiedenis der Nederlanden binnen het Rijk, compleet met Balderik en Dirk III. Het bevat daarnaast echter nuttige opmerkingen over de positie van de Brabantse hertogen na 1190. In de laatste paragraaf komt schrijver tot zijn eigenlijke onderwerp met een uiteenzetting van de rechtspositie van Brabant en Limburg vanaf de verlening van de zogenaamde Gouden Bulle van 1349 door Karel IV aan Jan III. Die werd gevolgd door een verder strekkend privilege van Sigismund en tenslotte één van Maximiliaan (1512) dat optreden van het RKG ten aanzien van inwoners van Brabant cum annexis geheel of vrijwel geheel uitsloot en dat in de Nederlanden zijns gelijke niet had.

Vervolgens stelt de auteur het Verdrag van Augsburg aan de orde, dat de Bourgondische Nederlanden aan de jurisdictie van het Rijk onttrok. Het is niet zonder meer duidelijk, welke gewesten en heerlijkheden onder de nieuwe kreits ressorteerden. Om een betere kijk op de situatie te kunnen geven, onderzocht Nève allereerst welke territoria volgens de rijksbelastingengegevens behoorden tot de zogenaamde eerste Bourgondische kreits van 1512 (die voor de jurisdictie van het RKG geen consequenties had). De afbakening ten opzichte van de Westfaalse kreits - waartoe immers Gelderland, Sticht en Oversticht, Friesland en Groningen behoorden - blijkt ook voor de tijdgenoten moeilijk te zijn geweest. Ook na het Verdrag van Augsburg bleef enige verwarring bestaan, nu over de vraag wie onder de Bourgondische landen gerekend dienden te worden en welke heren uit de 'oude' kreits thans aanspraak konden maken op een 'rijksonmiddellijke' status. In 70 helder geformuleerde bladzijden gaat schrijver voor ruim 25 heerlijkheden afzonderlijk na, aan de hand van literatuur en gedrukte bronnen, of zij aan de jurisdictie van het Rijk onderworpen bleven, criterium voor hun souvereiniteit binnen het verband van het Rijk. Het 